\title{
A dignidade da pessoa humana e a necessidade de um diálogo jurídico- filosófico ${ }^{1}$
}

\author{
Luana Michelle da Silva Godoy ${ }^{2}$
}

\begin{abstract}
Resumo
A dignidade da pessoa humana é fundamento do Estado democrático de Direito, da República Federativa do Brasil e valor-fonte do ordenamento jurídico. Ocorre que a natureza aberta da terminologia dignidade causa a sensação de incerteza e insegurança, fomentando uma vasta discussão doutrinária referente a esta problemática. A dignidade antecede a positivação jurídica e envolve questões complexas que não podem ser abarcadas de forma satisfatória pelo direito. Por isso esse artigo busca demonstrar a importância do diálogo-jurídico filosófico na abordagem do valor constitucional em análise.
\end{abstract}

Palavras Chave: Dignidade da pessoa humana; Direito; Filosofia.

\section{Introdução}

A dignidade é intrínseca ao ser humano, o que faz com que este tenha direito ao respeito da comunidade e do Estado. O ordenamento jurídico reconheceu esse fato mediante a positivação de direitos fundamentais protetores. Dessa forma o Estado deve respeitar os direitos fundamentais e promover políticas públicas para proporcionar uma existência digna aos indivíduos.

Ocorre que natureza aberta da terminologia "dignidade" facilita a sua utilização de forma indiscriminada, o que causa a sua hipertrofia e dificulta a sua aplicação. Por isso estudar traços delimitativos no que concerne a dignidade da pessoa humana é inerente à manutenção da segurança jurídica no Estado Democrático de Direito.

Por mais dificuldades que a delimitação do conteúdo desse valor enfrente, a atividade jurisdicional é provocada para atuar nos casos concretos, acarretando conseqüências jurídicas no mundo dos fatos.

${ }^{1}$ Este trabalho é inspirado nas pesquisas efetuadas no projeto de pesquisa ESTADO E RELAÇÕES EM PRESARIAIS: DIÁLOGOS FILOSÓFICOS E JURÍDICOS DIANTE DA REGULAÇÃO ESTATAL SOBRE A ORDEM ECONÔMICA do Curso de Mestrado em Direito Negocial da Universidade Estadual de Londrina, sob a coordenação dos Professores Doutores Bianco Zalmora Garcia, Clodomiro José Bannwart Jr., Elve Miguel Cenci e Marlene Kempfer Bassoli.

2 Mestranda em Direito Negocial na Universidade Estadual de Londrina - UEL, bolsista pela CAPES. 


\section{A dignidade da pessoa humana: dificuldades conceituais}

A constituição mexicana de 1917 se referia a dignidade da pessoa humana como valor que deveria orientar o sistema educacional do país. A Constituição italiana de 1947 preconizava no seu artigo 3o que todos os indivíduos possuem a mesma dignidade social frente à lei. Mas foi a Constituição Alemã de 1949 que pela primeira vez se referiu a dignidade da pessoa humana como direito fundamental no seu artigo 1으, inciso I: "A dignidade humana é inviolável. Repará-la e protegê-la é obrigação de todos os poderes estatais" (M ARTINS, 2003, p. 34).

A Constituição de Portugal, Espanha, Bélgica, Irlanda, Peru, Venezuela, entre outras tantas passaram a prever expressamente a dignidade da pessoa humana. Na França a admissão da dignidade foi fruto de criação jurisprudencial (M ARTINS, 2003, p. 35).

No Brasil, a Constituição de 1988 foi a primeira a tratar da dignidade da pessoa humana como fundamento da República e do Estado democrático de Direito. As constituições anteriores se referiam a questão de modo mais superficial, cite-se a de 1934 que preconizava no artigo 115 que a ordem econômica deveria se organizar de modo a permitir a existência digna de todos. A Constituição de 1947 referia-se à dignidade defendendo que esta deveria ser proporcionada mediante a garantia do trabalho humano (art. 145). A menção da terminologia dignidade humana foi abordada pela primeira vez no Brasil na Constituição de 1967. Ressalta-se que a positivação da dignidade não serviu de óbice para os abusos do Estado autoritário da época. (M ARTINS, 2003, p. 48).

Porém, foi a Constituição de 1988 que instituiu a dignidade como valor-fonte do ordenamento jurídico, estabelecendo a mesma como fundamento da República e do Estado Democrático de Direito.

0 valor da dignidade da pessoa humana sobressai-se no ordenamento jurídico vigente e serve como principal parâmetro de harmonização para os demais princípios constitucionais. Portanto está presente o seu caráter instrumental, uma vez que deve ser utilizado na interpretação e aplicação dos valores constitucionais.

[...] Em face da Constituição de 1988, por força de sua proeminência axiológica sobre os demais valores, temos que uma das principais funções do princípio da dignidade da pessoa humana repousa, então, na circunstância de ser elemento que confere unidade de sentido e legitimidade em determinada ordem constitucional. 
em suma, o valor da dignidade da pessoa humana confere uma unidade de axiológico-normativa de sentido à Constituição Brasileira (M ARTINS, 2003, p. 62).

Além da função supramencionada o referido valor funciona como uma cláusula aberta para apoiar o surgimento de novos direitos. "[...] acaba sendo um instrumento de estabilidade constitucional, permitindo a adaptação do conteúdo constitucional, sem a necessidade de reforma e alteração do texto, à evolução da sociedade e aos novos direitos que em teu seio são 'gerados'" (M ARTINS, 2003, p. 67).

De acordo com as características de uma determinada sociedade existem valores que possuem destaque em relação aos demais. No sistema brasileiro o valor-fonte do direito é a dignidade da pessoa humana. Isso resta verificado pela sua localização no texto constitucional e pela positivação dos direitos fundamentais que consiste na concretização da dignidade da pessoa humana.

A dignidade da pessoa humana é o objetivo máximo do Estado brasileiro, pois é fundamento da República. Isso significa que o ser humano prevalece em relação aos bens materiais, que o Estado deve se abster de iniciativas que prejudiquem o indivíduo, bem como deve tomar medidas que busquem a concretização do seu bem estar. A dignidade da pessoa humana constitui óbice para as condutas abusivas do Estado, bem como importa na obrigação de que este crie mecanismos para a proteção dos direitos fundamentais.

Assim sendo, tem-se por dignidade da pessoa humana a qualidade intrínseca e distintiva reconhecida em cada ser humano que o faz merecedor do mesmo respeito e consideração por parte do Estado e da comunidade, implicando, neste sentido, um complexo de direitos e deveres fundamentais que assegurem a pessoa tanto contra to do e qualquer ato de cunho degradante e desumano, como venham a lhe garantir as condições existenciais mínimas para uma vida saudável além de propiciar e promover sua participação ativa e co-responsável nos destinos da própria existência e da vida em comunhão com os demais seres humanos (SARLET, 2007, p.23)

A visualização do alcance da dignidade no seu aspecto negativo é menos dificultosa, pois é possível exemplificar uma conduta abusiva que desrespeite esse valor inerente ao indivíduo. Mas a questão primordial consiste em quais os mecanismos que devem ou podem ser aplicados para a efetivação da dignidade? A verificação da dignidade humana no seu aspecto positivo parece ser a pergunta mais difícil de ser respondida. 
Bernardo (2006, p.246) ressalta que o abuso da utilização da dignidade como argumento dificulta a sua utilização, e que o mais prudente seria a sua positivação em diversos setores do direito para possibilitar a sua aplicabilidade com maior efetividade.

Mas como regulamentar a dignidade da pessoa humana frente ao forte conteúdo axiológico dessa terminologia, bem como a sua natureza aberta que limita a visualização do alcance de seu conteúdo?

O estudo jurídico não parece possuir elementos suficientes para apaziguar esses questionamentos, no entanto, esse fato não diminui a relevância dessa temática para 0 direito, dado que este é provocado a manifestar-se frente aos casos concretos.

\section{A dignidade da pessoa humana e a importância da filosofia}

Independente da crença, nacionalidade, gênero ou origem social, todos os indivíduos devem ter a sua dignidade respeitada. Assim preconiza 0 artigo $1^{\circ}$ da Declaração Universal da ONU (1948), segundo o qual "todos os seres humanos nascem livres e iguais em dignidade e direitos. Dotados de razão e consciência, devem agir uns para com os outros em espírito e fraternidade".

A dignidade, como qualidade intrínseca da pessoa humana, é irrenunciável e inalienável, constituindo elemento que qualifica o ser humano como tal e dele não pode ser destacado, de tal sorte que não se pode cogitar a possibilidade de determinada pessoa ser titular de uma pretensão a que lhe seja concedida a dignidade (SARLET, 2007, p. 6)

A dignidade é elemento indissociável da pessoa e antecede ao reconhecimento e positivação pelo direito, por isso uma abordagem estritamente jurídica não é suficiente para tratar dessa temática de forma satisfatória, sendo necessária à verificação de alguns aspectos filosóficos que envolvem a questão.

[...] a dignidade da pessoa humana não é uma criação constitucional, mas um dado preexistente a toda experiência especulativa, que em face da sua relevância e conteúdo filosófico, foi constitucionalizado como fundamento da República Federativa do Brasil, a qual se constituiu em Estado democrático de Direito (MARTINS, 2003, p. 15). 
Nas três ou quatro décadas que se passaram houve um grande processo de especialização e diferenciação no direito. M uitos temas que pertenciam à filosofia do direito foram inseridos na teoria do direito. Além desse fenômeno, o fracionamento interno na teoria do direito aumentou consideravelmente (ZACCARIA, 2004, p. 18).

A modernidade tem sido marcada com a ampla especialização das ciências. No entanto, desse acontecimento surgiu um paradoxo: a necessidade de redescobrir as conexões entre essas disciplinas. Também nasceu a imprescindibilidade de criar uma teoria capaz de envolver a teoria do direito e a filosofia. (ZACCARIA, 2004, p. 21).

0 estudo da dignidade da pessoa humana reacende a necessidade de estabelecer um diálogo entre o direito e a filosofia, pois o primeiro é incumbido de regular questões que são abordadas de forma muito mais ampla pelo estudo filosófico.

Platão afirma que a filosofia é "o uso do saber em proveito do homem". Para o mesmo não adianta obter a informação de como se transformar pedra em ouro, se não souber utilizar o ouro. Devido a isso é imprescindível uma ciência que "que coincidam fazer e saber utilizar o que é feito e essa ciência é a filosofia" (apud ABBAGNAM 0, 2007, p. 514).

"A filosofia revela a sua capacidade de pensar sobre o próprio pensamento". No entanto, a sua função não se exaure neste momento, uma vez que também se voltam à análise do comportamento humano nos seus mais variados aspectos (GOM ES, 2008, p. 42).

E assim sendo, a construção do discurso, na perspectiva filosófica, não como se resumir a um mero relato do que disseram os grandes filósofos sobre o que se pretende falar. Nem pode se ater a um puro subjetivismo solipsista de quem queira filosofar. Pressupõe o diálogo com pensadores que se pôde conhecer e que disseram algo a respeito da temática que se faz objeto da reflexão a fim de que se possa contar com o auxilio deles no enfrentamento das questões. Em tal diálogo, quem pretende tratar sobre determinado tema há de procurar formular, sem receio as perguntas necessárias e adequadas. É-lhe muito mais importante ser capaz de perguntar, do que de obter, apressadamente, respostas. A preponderância das perguntas sobre as respostas faz parte da atitude zetética inerente ao ato de filosofar, independentemente de qual seja o objeto de tal filosofia. Isso vale também para a filosofia do direito (GOMES, 2008, p. 45).

Para Dworkin os argumentos filosóficos apresentam-se inevitáveis quando se discutem questões altamente polêmicas. Existem momentos que exigem novos juízos e reflexões mais profundas. No Direito constitucional, por exemplo, é comum encontrar 
situações em que se clame por um novo juízo, devido à inexistência de precedentes ou doutrina satisfatória (DWORKIN, 2000, p. 1-5).

0 mesmo autor também defende que ao utilizar argumentos filosóficos, as finalidades dos juristas e filósofos se diferenciam, pois o escopo dos primeiros não se funda na busca da melhor estruturação de uma teoria e sim na utilização desta para auxiliar em dilemas jurídico. No entanto, os juízes e os filósofos são semelhantes uma vez que ambos buscam esclarecer os conceitos fundamentais presentes na moralidade política e na legislação vigente (DWORKIN, 2000, p. 2-5).

Faz-se relevante o reconhecimento da importância dos estudos filosóficos, o que não significa afirmar que os juristas devem adotar a linguagem filosófica, ou algum autor determinado. A filosofia deve servir para iluminar a discussão ou pelo menos para estruturála da forma mais coerente.

Tendo em vista a necessidade da interdisciplinaridade deve se ressaltar de modo exemplificativo a contribuição da filosofia no estudo do direito e da dignidade da pessoa humana.

\section{Algumas contribuições do pensamento filosófico}

A natureza da justiça e do direito despertaram interesse desde os primórdios dos tempos. A importância do da análise deste tema na Grécia antiga deve-se à imensurável profundidade filosófica dos estudos advindos dessa época, que são responsáveis por contribuições sentidas até os dias atuais.

Ainda que os gregos não se preocupassem diretamente com o conceito de dignidade existiu a tentativa de construir uma visão de "um homem com validade universal e normativa". Está presente uma importante contribuição para o estudo do significado de dignidade que é intrínseco ao ser humano, uma vez que a análise daquela pressupõe o estudo do indivíduo (M ARTINS, 2003, p. 21).

A filosofia grega inova com um modo de pensar diferenciado, visto que a explicação mediante argumentos míticos é o que prevalecia até então. É introduzido o "logos" e o agir humano passa a ser racionalizado (M ARTINS, 2003, p. 21).

Durante um considerável período, o direito e a religião formavam um todo único. Tanto a atividade legislativa quanto a jurisdicional eram exercidas juntamente com ritos 
religiosos, atribuindo-se relevante papel aos sacerdotes. As crenças religiosas eram consideradas como verdadeiras leis não escritas. No século V A.C, a filosofia afastou-se da religião, e a tradição grega sofreu uma análise crítica. A lei passou a ser vista como construção humana, e a justiça despida de características metafísicas e associada aos aspectos psicológicos do homem, bem como aos interesses sociais envolvidos. Essa mudança foi obra dos sofistas "que podem ser considerados os primeiros representantes do cepticismo e relativismo filosófico" (BODENHEIM ER, 1966, p. 19).

A distinção entre a natureza e a lei constitui legado dos sofistas, com destaque para Antifo que ressaltava que o homem que descumpre a lei da natureza, inevitavelmente sofre as conseqüências, mas quem viola a lei do Estado só será punido se os seus atos se tornarem conhecidos. "Implícita neste argumento está a presunção de que as convenções humanas nada mais são do que grilhões da "lei" natural". (BODENHEIM ER, 1966, p. 21).

Platão, discípulo de Sócrates, busca diferenciar claramente as idéias de justiça e de Lei. A sua teoria de justiça detalhada é pilar da sua filosofia, e não sofreu modificação no decorrer de toda a sua existência, ao contrário da sua concep ção em relação à lei que passou por diversas transformações. Para aquele a justiça ocorre quando o homem cumpre a sua função conforme a posição determinada por sua aptidão. Cada indivíduo possui uma atribuição peculiar na sociedade, sendo que deve se restringir a buscar a sua concretização da melhor forma possível. Alguns possuem a aptidão de governar, outros de se dedicarem às artes, ou comércio, ou de ajudar o governante. Essas classes diferenciadas de indivíduos na sociedade, de acordo com Platão, são estabelecidas pela diferenças naturais entre os homens.

Os governantes devem ser filósofos, uma vez que sem a filosofia não é possível combater os males do Estado A autoridade do governo não pode sofrer restrições, em nome do bem público. Os homens do governo para Platão representam o ouro. Os militares, que são os auxiliares do governo são os homens de prata e as classes produtoras são o ferro e 0 cobre. Os homens de ouro e de prata deverão abdicar da família e da propriedade privada e as suas uniões com mulheres deverão ser reguladas pelo Estado por razões de eugenia, as demais classes podem constituir família e possuir propriedade sob a fiscalização do Estado (BODENHEIM ER, 1966, p. 22). 
Na obra "A República", Platão admite que mesmo nessa "comunidade ideal" podem surgir conflitos. Neste caso, os juízes devem agir com "discrição", não sendo a atividade jurisdicional limitada pela lei, uma vez que o Estado será governado pelos melhores cidadãos. Para Platão, conforme a exposição na sua obra "O Estadista", a lei não consegue regular todas as possibilidades existentes dada às complexidades dos homens, dos negócios, a modificação dos tempos etc. Por isso é mais plausível que a lei não seja absoluta e que a decisão fique ao crivo de um homem dotado de aptidão para a atividade governamental. No entanto, nos últimos dez anos da sua vida, Platão admite a necessidade de existência de um "Estado Legal", visto a dificuldade de encontrar um homem com todas as qualificações de um governante apto (BODENHEIMER, 1966, p. 23).

Aristóteles foi educado pela academia de Platão, recebendo as suas influências. No entanto, aprimora o "idealismo e racionalismo" do seu mestre salientando a realidade social, bem como os aspectos maléficos do homem e das suas instituições.

Segundo este filósofo o Estado emoldurado por Platão não lograria êxito diante das imperfeições inerentes à natureza humana. Dessa forma, o direito apresenta-se como mecanismo possível para alcançar a organização política (BODENHEIM ER, 1966, p. 24).

0 poder soberano é a lei de acordo com Aristóteles, só sendo possível prevalecer a vontade individual quando a situação fática não for alcançada pela regulação de lei de ordem geral. Apesar de concordar com Platão no que concerne ao governo do Estado por um homem apto, Aristóteles defende que este deve editar leis, deve existir um corpo de normas, pois o homem pode ser dominado por paixões (BODENHEIM ER, 1966, p. 25).

Ocorre que 0 filósofo aludido admite que 0 caráter geral e absoluto das leis pode prejudicar gravemente um caso determinado, devido a sua generalidade. Nessa situação Aristóteles recomenda que se recorra a equidade, devendo o juiz agir conforme o legislador se tivesse previsto tal hipótese (BODENHEIM ER, 1966, p. 25).

Aristóteles diferencia justiça natural de convencional. Sendo que a primeira, ao contrário da segunda, não depende de aceitação, bem como é válida para todos indistintamente (BODENHEIM ER, 1966, p. 26).

Aristóteles não solucionou a questão em torno do embate entre norma natural e norma positiva, mas admite a existência de lei injusta (BODENHEIM ER, 1966, p. 26). 
A escola estóica foi fundada por Zenão (350-260 A. C). 0 pilar do estudo dos estóicos era constituído pelo conceito de natureza. Consoante o entendimento dessa escola, a natureza é o princípio que rege todo o universo. Esse princípio, de acordo com Zenão, possui caráter racional. A razão é a "substância do Universo" e a lei da natureza não se distingue dessa substância. Logo, como o homem decorre dessa "natureza cósmica" este é racional, pois se norteia pelas leis da sua natureza (BODENHEIM ER, 1966, p. 27).

Os estóicos defendiam que o homem deveria se nortear pela racionalidade, e desfazer-se de todas as emoções e paixões, buscando harmonia interior, tornando-se "independente do mundo exterior e dos bens terrenos" (BODENHEIM ER, 1966, p. 27).

Para os estóicos a razão era "a base da lei e da justiça". Em todo indivíduo pode ser detectada a "razão divina", não importando raça ou nacionalidade. A lei da natureza, respaldada na razão vale para todo o "cosmo", e obriga indistintamente todo indivíduo (BODENHEIMER, 1966, p. 27).

Desenvolveram eles uma filosofia cosmopolita, baseada no principio da igualdade de todos os homens e na universalidade da lei natural. Seu ideal mais ato era um estadomundo, em que os homens vivessem juntos harmoniosamente sob o comando da razão divina (BODENHEIM ER, 1966, p. 27-28).

Cícero (106-43 A. C), destaca-se entre aqueles que sofreram fortes influências dos estóicos. Segundo aquele, a Lei possui força natural e rege todo o universo e a "característica do homem racional era a sua disposição de espírito para dar a cada um o que lhe pertence, atitude esta que para Cícero, era equivalente a justiça" (BODENHEIM ER, 1966, p. 28).

De acordo com os estóicos, o princípio da igualdade é um conteúdo relevante da lei natural, pois quaisquer discriminações entre os indivíduos são injustas e antagônicas à lei da natureza. Essa concepção estóica foi aderida parcialmente no Império Romano, fomentando transformações na idéia de escravidão e de família romana, traçando aspectos mais humanitários em relação a estes.

Não obstante a importância da filosofia grega, é no pensamento cristão que a temática da dignidade passa a ganhar maior dimensão. No cristianismo, o homem passa a ser considerado como imagem e semelhança de Deus, este por sua vez se diferencia dos Deuses gregos, uma vez que não possui os defeitos e as paixões humanas (M ARTINS, 2003, p. 22). 
A visão de universo preponderante na Idade Média possuía como base o Novo Testamento e os ditames da Igreja Católica. As doutrinas filosóficas e as ciências eram monopolizadas pela Igreja. No entanto, persistiram as influências de Platão, Aristóteles e dos estóicos em muitos pensadores medievais, ainda que sobe o lume de uma leitura adaptada a doutrina cristã.

Em uma epístola de Paulo aos romanos já se visualiza uma indicação de existência do direito natural quando defende que há uma lei presente no interior dos homens que os impulsionam a obediência a lei (Romanos, 2: 14-15). 0 referido texto respalda a idéia de que todo indivíduo possui um senso que lhe é inerente e o direciona, independentemente de lei escrita.

Para Agostinho a queda do homem fora marcada pelo pecado original. Neste momento os atributos benignos do ser humano não foram banidos, mas "a condição de existência", de que decorrem sentimentos maléficos tais como a gula, ambição entre outros, ganharam relevância. A morte passa a assolar a vida como um castigo divino. Assim, 0 exercício de um direito natural pleno resta prejudicado (BODENHEIMER, 1966, p. 36).

A impraticabilidade do direito natural absoluto justifica a busca de mecanismos e instituições que protejam a sua existência. “Governo, lei, propriedade e estado apareceram em cena; conquanto fossem radicalmente frutos do pecado, justificou-os Agostinho a luz das deterioradas condições da espécie humana" (BODENHEIM ER, 1966, p. 36).

Segundo Agostinho a Igreja prevalece sobre o estado, pois aquela protege a lei de Deus. Por isso o estado deve resguardar a Igreja, uma vez que esta visa buscar a ordem e a paz entre os homens. 0 Estado deve obediência a Igreja e deve buscar a concretização das leis terrenas, que por sua vez deve estar em consonância com a lei de Deus. Caso contrário não devem e não possuem nenhum conteúdo prescritivo (BODENHEIM ER, 1966, p. 36).

Agostinho explanava que a concretização plena da lei eterna não seria realizada. Não obstante, acreditava que futuramente a "comunidade mundana" soçobraria e prevaleceria "a comunidade divina" e a mácula causada pelo pecado de Adão seria abolida (BODENHEIM ER, 1966, p. 37).

A filosofia escolástica de São Tomás de Aquino (1226-1274) é marcada por pelas inestimáveis contribuições que persistem no decorrer dos tempos. Pode-se lhe atribuir 0 mérito de ter sintetizado os dogmas cristãos bíblicos e a filosofia aristotélica. As idéias de 
Aristóteles são adaptadas por Aquino, conforme os ensinamentos das doutrinas do evangélico.

Aquino dividiu as leis em quatro espécies: a lei eterna, a natural, a divina e a humana. A lei eterna representa a sabedoria divina comandando o universo, conhecido tão somente por Deus e talvez alguns "bem-aventurados". Ressalta-se que não obstante 0 homem não conheça essa lei, a "faculdade da razão" permite que o mesmo tenha uma noção desta. Essa conexão da racionalidade humana com a lei cósmica é denominada direito natural, que possibilita o homem acessar ao menos alguns princípios da lei eterna (BODENHEIM ER, 1966, p. 38).

0 direito natural permite ao homem diferenciar o bem do mal. De acordo com esse entendimento é inerente ao instinto do homem se inclinar para o bem. Citem-se como exemplos 0 instinto de conservação, de atrair-se pelo sexo oposto e procriar, de viver em sociedade (BODENHEIM ER, 1966, p. 38-39).

0 pensamento tomista considera os aspectos psicológicos, físicos e racionais do ser humano. A razão que impulsiona o homem à benignidade é considerado por São Tomás como um instinto natural. Assim, as virtudes do homem são interpretadas como decorrentes da lei natural, sendo que os atos maléficos são desvios que contrariam a natureza humana. A lei humana é "um ordenamento da razão para o bem comum, ditado e promulgado, por quem tenha a incumbência de cuidar a comunidade" (AQUINO apud BODENHEIM ER, 1966, p. 39).

São Tomás de Aquino utiliza a terminologia dignidade para designar como característica intrínseca ao ser humano. Afirmava que a racionalidade é o diferencial entre os homens e os demais animais, uma vez que aquele é responsável pelo seu destino (M ARTINS, 2003, p. 224).

$\mathrm{Na}$ conceituação de lei Aquino se aproxima de Aristóteles, uma vez que ambos inserem naquela o conceito de razão. A lei emanada por um governo deve se coadunar com a razão, pois "uma lei injusta ou desarrazoada, como a que repugne ao direito natural, não é lei, mas uma deturpação da lei" (BODENHEIM ER, 1966, p. 39).

Para Aquino Leis injustas não devem ser obedecidas, exceto nos casos em que a desobediência resulte em um mal coletivo maior. No entanto quando a lei for contrária aos desígnios de Deus, não pode de nenhuma forma ser cumprida (BODENHEIM ER, 1966, p. 40). 
A visão tomista de justiça aproxima-se claramente da de Aristóteles e de Cícero uma vez que defende que esta se caracteriza quando é "dado a cada um o que lhe pertence", bem como adere a divisão de justiça em contributiva e corretiva (BODENHEIM ER, 1966, p. 40).

Para o pensamento vigente nesta época todos são iguais perante Deus, independente das posses ou outras características. É mediante esta visão inovadora de igualdade que o cristianismo contribui para a busca do sentido da dignidade.

Kant ao abordar as ações humanas e as questões morais decorrentes destas contribuiu de forma inestimável para a visão de dignidade presente nos dias atuais. Para este pensador a dignidade constitui o maior valor do indivíduo, que não pode ser mensurado ou substituído (M ARTINS, 2003, p. 29).

Verifica-se que a visão ontológica da dignidade possui papel de destaque no pensamento filosófico, no entanto deve-se ser destacado uma outra dimensão.

De acordo com Sarlet, uma idéia que tem sido proposta para amenizar os problemas da dimensão ontológica-biológica da dignidade da pessoa humana até então presente é a visão intersubjetiva, que defende que é no âmbito das interações humanas que a dignidade possui maior relevância.

Habermans defende a importância da dimensão da intersubjetividade:

\begin{abstract}
Considerando que a dignidade da pessoa, numa acepção rigorosamente moral e jurídica, encontra-se vinculada à simetria das relações humanas, de tal sorte que a sua intangibilidade (o grifo é do autor) resulta justamente das relações interpessoais marcadas pela recíproca consideração e respeito, de tal sorte que apenas no âmbito do espaço público da comunidade da linguagem, o ser natural se torna indivíduo e pessoa dotada de racionalidade (SARLET, 2007, p. 11).
\end{abstract}

Habermans ao abordar as questões que envolvem as conseqüências do desenvolvimento biotecnológico diferencia dignidade humana da dignidade da vida humana. Sendo que a primeira se relaciona as questões que envolvem a interação de sujeitos de uma mesma comunidade, e a segunda possui uma concepção própria porque aborda questões que antecedem a vida humana. A questão da dignidade da vida humana deve estar relacionada a dilemas que vivenciadas pela autocomprensão humana em decorrência dos desenvolvimentos biotecnológicos (ANDRADE, 2005 p. 12). 
Outra questão que deve ser ressaltada é a dimensão cultural da dignidade, uma vez que a dignidade é uma construção histórica que depende do contexto social vigente. Por isso não é possível a construção de um conceito fechado de dignidade.

\begin{abstract}
[...] a dignidade da pessoa humana possui um sentido ontológico, intersubjetivo e ao mesmo tempo está em constante construção dado os aspectos culturais que a envolvem. Os direitos humanos não devem assegurar a dignidade, mas mecanismos que possibilitem a sua prestação considerando que a dignidade da pessoa, numa acepção rigorosamente moral e jurídica, encontra-se vinculada à simetria das relações humanas, de tal sorte que a sua intangibilidade (o grifo é do autor) resulta justamente das relações interpessoais marcadas pela recíproca consideração e respeito, de tal sorte que apenas no âmbito do espaço público da comunidade da linguagem, o ser natural se torna indivíduo e pessoa dotada de racionalidade (SARLET, 2007, p. 19).
\end{abstract}

\title{
Conclusões
}

A Constituição de 1988 ao estabelecer expressamente no artigo $1^{\circ}$, inciso III que a dignidade da pessoa humana constitui fundamento do Estado Democrático de Direito, priorizou a pessoa em detrimento de outros valores.

A dignidade é valor fonte do ordenamento jurídico e cláusula aberta de proteção à pessoa que significa que qualquer inovação jurídica ou interpretação normativa deve se compatibilizar com esse fundamento. Os princípios constitucionais protetores constituem reflexo da adoção da dignidade da pessoa humana no ordenamento jurídico brasileiro que seguiu o exemplo de outros vários ordenamentos jurídicos, que positivaram esse valor após as atrocidades nazi-fascistas.

Ocorre que a dignidade é utilizada como respaldo dos mais diversos argumentos jurídicos, muitas vezes antagônicos entre si, o que reafirma a importância da discussão doutrinária relativa ao alcance de seu conteúdo.

As dificuldades em formular traços delimitativos no que concerne a temática da dignidade da pessoa humana advêm da natureza polissêmica dessa terminologia o que prejudica a sua aplicação e fomenta até mesmo a sua hipertrofia. Dessa forma, a conceituação do valor dignidade não parece possível devido a sua natureza aberta e ao seu forte conteúdo axiológico. No entanto, não é plausível que esse óbice respalde a banalização mediante a utilização indiscriminada de argumentos que desvirtuem o seu conteúdo, tendo 
em vista que sob a afirmação da proteção desse valor condutas abusivas podem ser cometidas.

Ressalta-se que insegurança não corrobora com o Estado Democrático de Direito, uma vez que o cidadão deve ter o mínimo de parâmetro em relação à atuação estatal na efetivação de suas atribuições. Por isso o ordenamento jurídico e a atuação judicial devem ser permeadas da previsibilidade necessária à estabilidade das relações sociais.

Mas a dignidade antecede a positivação jurídica e constitui elemento inerente ao ser humano, por isso a contribuição filosófica torna-se imprescindível a abordagem dessa temática.

O pensamento filosófico analisa o homem no decorrer dos tempos, foi responsável pela separação entre razão e religião, bem como determinou que a dignidade é elemento intrínseco ao ser humano. Além disso apresenta a importância da análise das dimensões intersubjetiva e cultural da dignidade.

Por isso faz-se necessário um diálogo jurídico-filosófico para a dignidade seja abordada com a profundidade que o tema merece.

\section{Referências}

ABBAGNANO. Dicionário de filosofia. São Paulo: Martins Fontes, 2007. p. 326.

ANDRADE, Tales de. A crise da autocompreensão da espécie humana. Ambiente $\&$ sociedade, v. 8, n. 1, p. 11-14, jan./jun. 2005.

ANDRADE, Vander Ferreira. A dignidade da pessoa humana: valor-fonte da ordem jurídica. São Paulo: Cautela, 2007.

BERNARDO, Wesley de Oliveira. O princípio da dignidade humana e o direito civil: breves reflexões. Revista da faculdade de direito de campos, n. 8. p. 229-267, jun. 2006.

BODENHEIM ER, Edgar. Ciência do Direito. Filosofia e M etodologia Jurídicas. Tradução de Enéas Marzano. Rio de Janeiro: Forense, 1966. p. 2 -75; 149-182.

DW ORKIN, Ronald. Deben nuetros juces ser filósofos, pueden ser filósofos?. Traducción por Leonardo Jaramillo Garcia. New York: Conferencia pública en octubre 11 de 2000.

EM ERIQUE, Ĺlian Márcia Balmant; GUERRA, Sidney. 0 princípio da dignidade humana e o mínimo existencial. Revista da faculdade de direito de campos, n. 9, p. 379-397, dez. 2008. 
GOM ES, Sergio Alves. Hermenêutica constitucional: um contributo à constituição do Estado Democrático de Direito. Curitiba: Juruá, 2008.

JACINTO, Jussara M aria M oreno. Dignidade humana: princípio constitucional. Curitiba: Juruá, 2006.

M ARTINS, Flademir Jerônimo Belinati. Dignidade da pessoa humana: princípio constitucional fundamental. Curitiba: Juruá, 2005.

NUNES, Rizzato. 0 princípio constitucional da dignidade da pessoa humana: doutrina e jurisprudência. 2. ed. São Paulo: Saraiva, 2009.

PEZZ, Alexandra Cristina Giacomet Pezzi. Dignidade da pessoa humana: mínimo existencial e limites da tributação do Estado Democrático de Direito. Curitiba: Juruá, 2009. p. 17-42.

SARLET, Ingo Wolfgang. As dimensões da dignidade da pessoa humana: construindo uma construção jurídico-costitucional necessária e possível. Revista Brasileira de direito constitucional - RBDC, n. 9, p. 361-388, jan./jun. 2007.

ZACCARIA, Giussepe. Razón Jurídica e Interpretación. M adrid: Civitas, 2004. p. 17-32. 